\section{BMJ Paediatrics Open}

\title{
Management of infants born to mothers with SARS-CoV2 infection: a prospective observational study
}

Chokkiyil Ponnambath Hafis Ibrahim (10 , ${ }^{1}$ Fatma Oleks Lobko, ${ }^{1}$ Ghalia Abou Alchamat, ${ }^{1}$ Waleed Gamal Swilam, ${ }^{1}$ Saleema Rasool Wani, ${ }^{2}$ Soha Tohamy Said, ${ }^{2}$ Stefan Weber, ${ }^{3}$ Paul Bosio ${ }^{2}$

\section{ABSTRACT}

Objectives To assess the clinical risk of mother-to-infant transmission of SARS-CoV2 and transmission during rooming in and breast feeding in infants born to mothers with COVID-19.

Design Prospective observational study.

Setting A large tertiary maternal and neonatal care centre based in the UAE.

Participants Infants born to mothers diagnosed to have COVID-19 at the time of delivery, born between 1 April and 15 June 2020.

Revised 1 September 2020 Accepted 3 September 2020

Main outcome measures Rate of transmission of
Check for updates

(c) Author(s) (or their employer(s)) 2020. Re-use permitted under CC BY-NC. No commercial re-use. See rights and permissions. Published by BMJ.

${ }^{1}$ Neonatal Division, Corniche Hospital, Abu Dhabi, United Arab Emirates

${ }^{2}$ Obstetric Division, Corniche Hospital, Abu Dhabi, United Arab Emirates

${ }^{3}$ Reference Laboratory for Infectious Diseases, Sheikh Khalifa Medical City, Abu Dhabi, United Arab Emirates

Correspondence to Dr Chokkiyil Ponnambath Hafis Ibrahim; hafisibrahim@hotmail. com SARS-CoV2 from mother to infant (vertical or horizontal) while rooming in and breast feeding in hospital and post discharge and associated morbidity and mortality in the neonatal period.

Results 73 infants were born to mothers with COVID-19 at the time of delivery. Two infants tested positive for SARS-CoV2 after birth-one had respiratory symptoms related to other causes and the other infant remained well. 57 of mother-infant dyads who were well enough, roomed in while in hospital and all were breast fed. All surviving infants were followed up by telephone at 2 weeks and 4 weeks (or from the patient record review if still on the Neonatal Intensive Care Unit. Majority of the discharged infants were still rooming in with mothers $(95 \%$ at 2 weeks, $99 \%$ at 4 weeks) and still breast fed ( $99 \%$ at 2 weeks, $99 \%$ at 4 weeks). None of the infants developed any significant health issues or developed symptoms attributable to SARS-CoV2.

Conclusions The risk of mother-to-infant transmission of SARS-CoV2, vertically or horizontally, in the perinatal period is very low. Breast feeding and rooming in can be practised safely with adequate infection control precautions with negligible clinical risk to the infant.

\section{INTRODUCTION}

The novel SARS-CoV2 which leads to the clinical syndrome now labelled as COVID-19 was first detected in the Wuhan-Hubei province of China in December 2019. Since then, it has spread across the world with the WHO declaring it as a global pandemic on 11 March $2020 .^{1}$

Knowledge about the epidemiology and clinical presentation of COVID-19 is rapidly

\section{What is known about the subject?}

The risk of vertical transmission of SARS-CoV2 from mother to infant at the time of delivery is low.

\section{What this study adds?}

- Rooming in for infants born to mothers with COVID-19 is safe with adequate precautions.

- Breast feeding for infants born to mothers with COVID-19 is safe with adequate precautions.

evolving. Although the virus affects individuals across the age spectrum, it is becoming increasingly apparent that outcomes in adults are worse than in children. ${ }^{23}$ The vast majority of subjects infected display only mild symptoms or remain asymptomatic. ${ }^{4}$ Risk factors for higher morbidity and mortality in adults include older age and the presence of other underlying comorbidities including hypertension, coronary artery disease, diabetes, renal failure, malignancy and other immunocompromised states. ${ }^{45}$

Pregnant women are deemed to be in an immunocompromised state and data from previous corona virus epidemics (SARS-CoV and MERS-CoV) have shown that they were at a high risk of morbidity and mortality. ${ }^{6}$ The literature published so far on COVID19 , however, suggests that hospitalised pregnant women do not seem to be at a higher risk of adverse outcomes compared with hospitalised non-pregnant individuals. ${ }^{6-8}$ The risk of vertical transmission to infants born to mothers with COVID-19 seems low. ${ }^{7-11}$ In the few infants who tested positive following birth, it was not certain whether the transmission was vertical or postnatal and further, the majority of these infants had only mild-tomoderate disease. 
The first case of COVID-19 was detected in the United Arab Emirates in January 2020 in a family returning from China. Since then, community transmission has become established within the country. The response to the pandemic within the country has evolved in a pragmatic way as the dynamics of the disease in the community evolved and new knowledge became available. The underlying principle has been of mass testing, contact tracing and strict isolation, either in a designated quarantine facility or at home with centralised monitoring and coordination. Symptomatic patients were admitted and treated at designated facilities. Corniche Hospital in Abu Dhabi is the largest tertiary maternity unit in the country with around 6000 deliveries per annum and was designated as the healthcare facility for pregnant women affected by COVID-19 within the Emirate. The hospital started receiving pregnant women infected with SARS-CoV2 by the end of March 2020 and the first baby born to a mother infected with the virus was delivered in April 2020. Here, we present the short-term outcomes of infants born to mothers infected with SARS-CoV2 and the safety of a policy of rooming in and breast feeding such babies at our hospital.

\section{METHODS}

All infants born to mothers who tested positive for SARS-CoV2 during pregnancy from 1 April to 15 June 2020 were eligible to be included in the study. All pregnant women diagnosed with COVID-19 in the Emirate of Abu Dhabi were directly admitted to Corniche Hospital or transferred in from other hospitals if their condition permitted. In addition, all patients admitted to the hospital were screened for SARS-CoV2 regardless of clinical indication for admission. The test was performed using a single nasopharyngeal (NP) swab. SARS-CoV2 virus was diagnosed by real-time reverse-transcriptase PCR with detection of the $\mathrm{N}$ and ORFlab gene using the U-Top COVID-19 Detection Kit (Seasun Biomaterials, Daejeon, Korea) or the $\mathrm{E}$ and the $\mathrm{S}$ gene using the RealStar PCR (Altona Diagnostics, Hamburg, Germany). Interpretation of the result was performed according to the manufacturer's recommendation. If positive, mothers were tested again after 72 hours and continued at the same frequency as long as they remained positive. Once a negative result was obtained, they were retested in 24 hours and if the second test came negative, they were deemed true negative and no further tests done.

A mother was considered positive at the time of delivery if her most recent swab prior to delivery was positive or she only had one negative swab subsequent to a confirmed positive. Infants born to mothers who were positive at the time of delivery as defined above were admitted to the study and were tested for the virus at 24 hours of age using NP swab and RT-PCR. If positive, the same schedule of testing as for mothers was performed for the infants. The testing schedule was different for infants cared for on the postnatal ward and for those admitted to the NICU to facilitate the different infection control processes in the two areas. For infants cared for on the postnatal ward, if the initial test was negative, they were retested 24 hours after the first negative swab was obtained in the mother (along with the retesting for mother 24 hours after the first negative swab as detailed above)-this enabled the deisolating of both the mother and infant together. For infants admitted to the NICU, an initial test was also done at 24 hours of age and if negative, a repeat test done at 72 hours. If two tests were negative, the baby was considered negative for infection control purposes on NICU.

Infants who were well enough to be cared on the postnatal ward were allowed to room in with their mothers unless the mother expressed a strong wish not to or the mother was too critically unwell to care for the infant. Infants who roomed in were allowed to breast feed with adequate droplet and contact precautions in accordance with recommendations from professional bodies. ${ }^{12}$ This included caring for the infant in a separate baby cot which is placed at least 6 feet from the mother's bed, mother wearing a mask when in close proximity to the infant and performing hand hygiene with either soap and water or alcohol based gel prior to handling the baby. No visitors apart from health personnel with appropriate personal protective equipment were permitted in to the rooms while in hospital. The parents were advised to continue the same precautions at home after discharge till the mother was considered negative for COVID-19 and had been in isolation for 14 days from the second confirmed negative test. Infants admitted to NICU were given expressed breast milk as soon as it became available.

\section{Data collection and analyses}

The clinical outcome details and results of COVID-19 screening were collected from the electronic patient record. The parents were contacted by telephone at 2 weeks and at 4 weeks post delivery to enquire about the health of infants, any COVID-19 testing done post discharge on the infants and any healthcare facility visits. For infants still on NICU at 2 or 4 weeks of age, data were extracted from the electronic patient record. Informed consent was obtained from the parents for inclusion in the study and for telephonic contact post discharge. Data were collected on an electronic database and analysed. Results are presented as summary statistics.

\section{Patient and public involvement}

Patients or the public were not involved in the design, conduct, reporting or dissemination plans of our research.

\section{RESULTS}

A total of 98 mothers tested positive during pregnancy and delivered during the study period. Of these, one mother withdrew consent and data on the mother and baby were deleted from the study database. Of the remaining 97 mothers, 71 mothers were considered positive at the time 


\begin{tabular}{|c|c|}
\hline & $\mathrm{N}=71$ \\
\hline Age (years) & $31(21-40)^{*}$ \\
\hline Gravida & $3(1-11)^{*}$ \\
\hline Parity & $2(0-8)^{*}$ \\
\hline Gestation at first COVID+ test & $38(25+1 \text { to } 42)^{*}$ \\
\hline Gestation at delivery & $38+5(25+1 \text { to } 42+1)^{*}$ \\
\hline COVID symptoms at time of delivery & $23(32 \%) \dagger$ \\
\hline $\begin{array}{l}\text { Received medical treatment for } \\
\text { COVID }\end{array}$ & $21(30 \%) \dagger$ \\
\hline \multicolumn{2}{|l|}{ Mode of delivery } \\
\hline Vaginal spontaneous & $34(48 \%) \dagger$ \\
\hline Vaginal instrumental & $7(10 \%) \dagger$ \\
\hline Caesarean section & $30(42 \%) \dagger$ \\
\hline
\end{tabular}

*Median (range).

†Number (percentage).

of delivery. Three were twin pregnancies with one having suffered an in-utero demise of one fetus. Hence, a total of 73 infants were born from mothers who were considered to be positive for positive for SARS-CoV2 at the time of delivery based on the testing regimen in practice at the hospital. The maternal characteristics are summarised in table 1 . There was one maternal death in this cohort.

The infant characteristics are summarised in table 2. Out of the 73 infants, 15 were admitted to intensive care unit-most of these (33\%) for transient tachypnoea and/or prematurity $(47 \%)$. One of the premature deliveries was a perimortem caesarean section on a mother in critical care. Of the 58 infants cared for on the postnatal ward, all but one roomed in with their mothers and all of them were breast fed. One infant was cared for by ward staff until discharge as the mother was mechanically ventilated in intensive care. In total, 71 of the 73 infants (97\%) received breast milk-breast either directly if rooming in with mother or via expressed breast milk if admitted to NICU. At the time of writing the report, the discharge outcomes of 68 infants were known at 4 weeks while 5 infants were still in hospital due to prematurity. Two infants had congenital malformations attributable to chromosomal abnormalities-one infant with Down syndrome and one with Turners syndrome. One infant born at 26 weeks gestation died from necrotising enterocolitis.

Two infants tested positive for SARS-CoV2 at 24 hours post delivery. One of them was a child with Down Syndrome delivered with reported intrapartum meconium stained liquor. He was admitted to NICU for respiratory distress requiring oxygen support. He remained in oxygen for 12 days and was diagnosed with a complete AVSD on echocardiography. There were no signs of any lung parenchymal changes on his X-ray and his oxygen requirement was deemed to be due to delayed adaptation associated with Down syndrome. He was successfully discharged home in room air. The second infant was a

\begin{tabular}{|c|c|}
\hline & $\mathrm{N}=73$ \\
\hline Birth weight in grams & $3050(700-4011)^{*}$ \\
\hline Gestation (weeks+days) & $38+5(25+1 \text { to } 42+1)^{\star}$ \\
\hline Preterm (<37 weeks) & $11(15 \%) \dagger$ \\
\hline Late preterm (32-36+6) & $7(10 \%) \dagger$ \\
\hline Very preterm $(28-31+6)$ & $3(4 \%) \dagger$ \\
\hline Extreme preterm (<28 weeks) & $1(1 \%) \dagger$ \\
\hline \multicolumn{2}{|l|}{ Apgar scores } \\
\hline $1 \mathrm{~min}$ & $9(0-9)^{*}$ \\
\hline $5 \mathrm{~min}$ & $10(2-10)$ * \\
\hline Male:female & 43 (59\%):30 (41\%)† \\
\hline Positive SARS-CoV2 test after birth & $2(3 \%) \dagger$ \\
\hline Admitted to NICU & $15(18 \%) \dagger$ \\
\hline \multicolumn{2}{|l|}{ Indication for admission } \\
\hline Prematurity & $7(47 \%) \dagger$ \\
\hline Resp distress & $5(33 \%) \dagger$ \\
\hline $\begin{array}{l}\text { Mild Hypoxic Ischaemic } \\
\text { Encephalopathy }\end{array}$ & $1(7 \%) \dagger$ \\
\hline Hypoglycaemia & $1(7 \%) \dagger$ \\
\hline Sepsis & $1(7 \%) \dagger$ \\
\hline Roomed in with mother in hospitalf & $57(98 \%) \dagger$ \\
\hline Breast fed at the time of discharge $\neq$ & $57(98 \%) \dagger$ \\
\hline Congenital malformations & $2(3 \%) \dagger$ \\
\hline All cause mortality & 1/73 (1\%)† \\
\hline
\end{tabular}

*Median (range).

$†$ Number (percentage).

$\ddagger$ Of the infants cared for on postnatal ward $\mathrm{N}=58$.

term baby who was completely asymptomatic at birth. He continued to have positive tests on repeat screening for the first 2 weeks of life but remained asymptomatic.

Follow-up data were available on all 72 infants who survived at at 2 and 4 weeks. The follow-up data collected at 2 weeks and 4 weeks are summarised in table 3 .

Six and five of the 72 infants were still on NICU at the time of follow-up at 2 weeks and 4 weeks, respectively, due to prematurity. The majority of discharged infants continued to room in with their mothers and were also breast feeding at both interrogation time points. Despite this, none of the infants developed any health problems. One infant was tested for SARS-CoV2 between 2 and 4 weeks due to exposure to another family member who had tested positive. This baby was asymptomatic and also tested negative for the virus.

\section{DISCUSSION}

Since the outbreak of SARS-CoV2 in China, governments and healthcare bodies and professionals have been continuously adapting and updating their approach to the management of the pandemic and individual patients as the situation evolved. One of the strategies 
Table 3 Follow-up data on surviving infants at prespecified time points ( 2 weeks and 4 weeks age)

\begin{tabular}{lll}
\hline N=72 & At 2 weeks & $\begin{array}{l}\text { At } 4 \\
\text { weeks }\end{array}$ \\
\hline $\begin{array}{l}\text { Still on NICU at follow-up } \\
\begin{array}{l}\text { At home or quarantine facility at } \\
\text { follow-up }\end{array}\end{array}$ & $66(8 \%)$ & $5(7 \%)$ \\
$\begin{array}{l}\text { Rooming in with mother at home or } \\
\text { quarantine facility }\end{array}$ & $63(95 \%)$ & $66(93 \%)$ \\
$\begin{array}{l}\text { Breast feeding on follow-up } \\
\text { (discharged infants) }\end{array}$ & $65(99 \%)$ & $66(99 \%)$ \\
$\begin{array}{l}\text { On breastmilk at follow-up (all infants } \\
\text { including infants on NICU) }\end{array}$ & $68(94 \%)$ & $67(93 \%)$ \\
$\begin{array}{l}\text { Health concerns post discharge } \\
\begin{array}{l}\text { Any other family member tested } \\
\text { positive for COVID-19 post discharge }\end{array}\end{array}$ & $9(14 \%)$ & $1(1 \%)$ \\
$\begin{array}{l}\text { Any infant COVID-19 negative at birth } \\
\text { tested positive for COVID-19 post } \\
\text { discharge }\end{array}$ & Nil & Nil \\
\hline
\end{tabular}

across the world was to target high-risk groups in order to try and reduce the morbidity and mortality faced by patients from such groups. Despite initial concern that pregnant women and the newborn may be high-risk groups compared with the general population based on outbreaks of other coronavirus diseases in the past, it has become increasingly clear that this is not the case with the SARS-CoV2 pandemic. $^{6-11}$

The risk of vertical transmission of the virus from mother to infant before or during delivery has been shown to be low. ${ }^{7-11}$ This has been confirmed based on virus testing and clinical features in our cohort, with the estimated risk being only $2.7 \%$ (2/73). This figure seems to be similar to previously published data. ${ }^{6913}$ One infant remained completely asymptomatic and the other infant had symptoms which could be attributed to other causes. Hence, even in infants who may be colonised with the virus at the time of delivery, the risk of disease seems minimal. The low risk of vertical transmission has been hypothesised to be due to paucity of ACE2 receptors in the placenta which may be necessary for transplacental transfer to the fetus. ${ }^{9}$ Regardless of the above, it would appear from our series that the short-term clinical risks to the infant from maternal COVID-19 at the time of delivery are minimal.

Due to the uncertainty surrounding the outcomes of mothers affected by COVID-19 and their infants, recommendations on the postnatal management of the mother-infant dyad from professional bodies have been inconsistent. ${ }^{12}$ 14-17 Some guidelines advocate caring for the affected mothers and their infants in separate rooms when feasible to reduce the risk of mother-infant transmission postnatally and also recommend avoiding direct breast feeding while mother is still infected, unless mother expresses her wish to directly breast feed. ${ }^{16}$ At our hospital, we deemed that the benefits of both rooming in and breast feeding with good infection control precautions, for mother-infant bonding and long-term breast feeding far outweighed the small risk of mother-infant transmission. Thus, we strongly recommended rooming in and direct breast feeding for all well mother-infant dyads while in hospital as well as after discharge. Our study has validated this approach with no clinically or laboratory-proven mother to infant transmission of the virus during the hospital stay and on follow-up to 4 weeks, even with a very high rate of breast feeding in the discharged infants. Moreover, it could be hypothesised that protective factors secreted in breastmilk may actually be protective as there were 10 babies in the cohort whose other family members were subsequently diagnosed with COVID-19 and yet the infants remained asymptomatic.

To our knowledge, this study is the single largest series on the outcomes of infants born to mothers with COVID-19 with follow-up of their health status post discharge. However, our study has limitations. The diagnosis of COVID-19 and virus carriage was based on NP swabs. Though the absolute sensitivity of detecting SARS-CoV2 with NP swabs is unknown, the modality is only around $70 \%$ sensitive for diagnosing respiratory viral infections. ${ }^{18}$ Nevertheless, since all admissions were being screened in addition to all symptomatic subjects also being tested (multiple times if clinically indicated), we feel that we have not missed any moderate to severe cases admitted to our centre. Although our cohort contained a full spectrum of maternal clinical presentations from mild to severe disease, the study is observational and clearly not powered to detect uncommon adverse clinical outcomes in the neonate. The universally good clinical outcomes in all the infants are nevertheless encouraging. The follow-up of infants was conducted by telephonic interview of the parents. There is a chance that asymptomatic and mildly symptomatic infants infected with the virus may have been missed in the absence of testing, although we would suggest that this is of limited clinical significance.

The risk of mother-to-infant transmission of SARS-CoV2, vertically or horizontally, in the perinatal period is very low. Breast feeding and rooming in can be practised safely with adequate infection control precautions. The risk of adverse outcome to infants born to mothers who have SARS-CoV2 infection at birth is minimal aside from the risk of premature delivery due to iatrogenic/ maternal reasons. However, there are no published longterm outcome data on these infants and further follow-up studies will be needed to fully ascertain any downstream adverse outcomes in this group of infants.

Contributors CPHI: consultant neonatologist conceived the project, assisted in drafting the protocol, data collection, analysed data, drafted the initial manuscript and approved the final manuscript as submitted. FOL drafted the protocol, contributed to data collection, reviewed and revised the manuscript, and approved the final manuscript as submitted. GAA and WGS contributed to data collection, reviewed and revised the manuscript, and approved the final manuscript as submitted. SRW provided the obstetric data, reviewed and revised the manuscript, and approved the final manuscript as submitted. STS: consultant 
obstetrician assisted with the obstetric data, reviewed and revised the manuscript, and approved the final manuscript as submitted. SW assisted with processing the virology samples, contributed to manuscript drafting, reviewed and revised the manuscript, and approved the final manuscript as submitted. PB assisted in drafting the research protocol, drafting the manuscript, reviewed and revised the manuscript, and approved the final manuscript as submitted.

Funding The authors have not declared a specific grant for this research from any funding agency in the public, commercial or not-for-profit sectors.

Competing interests None declared.

Patient and public involvement Patients and/or the public were not involved in the design, or conduct, or reporting, or dissemination plans of this research.

Patient consent for publication Not required.

Ethics approval The study was approved by the institutional research ethics committee.

Provenance and peer review Not commissioned; externally peer reviewed.

Data availability statement Data are available upon reasonable request. The anonymised data for this study can be made available on request for review subject to local regulatory requirements.

Open access This is an open access article distributed in accordance with the Creative Commons Attribution Non Commercial (CC BY-NC 4.0) license, which permits others to distribute, remix, adapt, build upon this work non-commercially, and license their derivative works on different terms, provided the original work is properly cited, appropriate credit is given, any changes made indicated, and the use is non-commercial. See: http://creativecommons.org/licenses/by-nc/4.0/.

ORCID iD

Chokkiyil Ponnambath Hafis Ibrahim http://orcid.org/0000-0002-7447-4466

\section{REFERENCES}

1 World Health Organisation. Coronavirus disease 2019 (COVID-19): situation report - 51, 2003. Available: https://www.who.int/docs/ default-source/ coronaviruse/situation-reports/20200311-sitrep-51covid19.pdf?sfvrsn=1ba62e57_10

2 Zhou F, Yu T, Du R, et al. Clinical course and risk factors for mortality of adult inpatients with COVID-19 in Wuhan, China: a retrospective cohort study. Lancet 2020;395:1054-62.

3 Ludvigsson JF. Systematic review of COVID-19 in children shows milder cases and a better prognosis than adults. Acta Paediatr 2020;109:1088-95.

4 Long L, Zeng X, Zhang X, et al. Short-term outcomes of COVID-19 and risk factors for progression. Eur Respir J 2020;55:2000990.

5 Guan W-J, Liang W-H, Zhao Y, et al. Comorbidity and its impact on 1590 patients with COVID-19 in China: a nationwide analysis. Eur Respir J 2020;55:2000547.
6 Zaigham M, Andersson O. Maternal and perinatal outcomes with COVID-19: a systematic review of 108 pregnancies. Acta Obstet Gynecol Scand 2020;99:823-9.

7 Huntley BJF, Huntley ES, Di Mascio D, et al. Rates of maternal and perinatal mortality and vertical transmission in pregnancies complicated by severe acute respiratory syndrome coronavirus 2 (SARS-Co-V-2) infection: a systematic review. Obstet Gynecol 2020;136:303-12.

8 Akhtar H, Patel C, Abuelgasim E, et al. COVID-19 (SARS-CoV-2) infection in pregnancy: a systematic review. Gynecol Obstet Invest 2020:1-12.

9 Egloff C, Vauloup-Fellous C, Picone O, et al. Evidence and possible mechanisms of rare maternal-fetal transmission of SARS-CoV-2. J Clin Virol 2020;128:104447.

10 Chen $\mathrm{H}$, Guo J, Wang C, et al. Clinical characteristics and intrauterine vertical transmission potential of COVID-19 infection in nine pregnant women: a retrospective review of medical records. Lancet 2020;395:809-15.

11 Schwartz DA. An analysis of 38 pregnant women with COVID-19, their newborn infants, and maternal-fetal transmission of SARSCoV-2: maternal coronavirus infections and pregnancy outcomes. Arch Pathol Lab Med 202010.5858/arpa.2020-0901-SA. [Epub ahead of print: 17 Mar 2020].

12 Royal College of Paediatrics and child Health. COVID-19 - guidance for neonatal settings, 2020. Available: <https://pubmed.ncbi.nlm.nih gov/?term=Royal+college+of+paediatrics+and+child+health+AND+ COVID>

13 Juan J, Gil MM, Rong Z, et al. Effect of coronavirus disease 2019 (COVID-19) on maternal, perinatal and neonatal outcome: systematic review. Ultrasound Obstet Gynecol 2020;56:15-27.

14 Davanzo R, Moro G, Sandri F, et al. Breastfeeding and coronavirus disease-2019: Ad interim indications of the Italian Society of Neonatology endorsed by the Union of European Neonatal \& Perinatal Societies. Matern Child Nutr 2020;16:e13010.

15 Centre for Disease control and prevention. Evaluation and management considerations for neonates at risk for COVID-19, 2020. Available: <https://www.cdc.gov/coronavirus/2019-ncov/hcp/ caring-for-newborns.html>

16 American Academy of Pediatrics. Management of infants born to mothers with suspected or confirmed COVID-19, 2020. Available: < https://services.aap.org/en/pages/2019-novel-coronavirus-covid-19infections/clinical-guidance/faqs-management-of-infants-born-tocovid-19-mothers/>

17 Wang L, Shi Y, Xiao T, et al. Chinese expert consensus on the perinatal and neonatal management for the prevention and control of the 2019 novel coronavirus infection (first edition). Ann Transl Med 2020;8:47.

18 Lieberman D, Lieberman D, Shimoni A, et al. Identification of respiratory viruses in adults: nasopharyngeal versus oropharyngeal sampling. J Clin Microbiol 2009;47:3439-43. 